Vol. 23, No. 1, Maret 2020, hlm. 45-53

p-ISSN: 1410-9344; e-ISSN: 2549-5631

homepage: http://journals.ums.ac.id/index.php/warta

\title{
WARTM LPU
}

\section{Deteksi Dini Penyakit Jantung Koroner di Desa Kalimanggis dan Madiasari Kabupaten Tasikmalaya}

\author{
Nur Lina, Dian Saraswati \\ Program Studi Kesehatan Masyarakat Universitas Siliwangi \\ Email:nurlina@unsil.ac.id
}

\begin{abstract}
Article Info
Submitted: 110ktober 2019

Revised: 23 Oktober 2019

Accepted: 23 Desember 2019

Published: 23 Januari 2020
\end{abstract}

Keywords: awareness, $C H D$, hypertension
Kata kunci: deteksi dinis, PJK, Hipertensi

\section{Abstract}

Coronary heart disease (CHD) is a disease caused by plaque that builds up in the coronary arteries that supplies oxygen to the heart muscle. One of the basic steps in controlling CHD is by screening for hypertension, which is blood pressure testing, and education by carrying out activities of IbBM Awareness of heart disease in patients with hypertension which is education to find hypertension which is very useful in order to encourage hypertension sufferers to seek treatment to prevent heart disease. . Awarenes heart disease is part of the management of non-communicable diseases, especially heart disease. The implementation of IbBM activities was carried out in collaboration with 2 (two) community groups PKK of Kalimanggis Village, Manonjaya District and Madiasari Village, Kecamatang Cineam, Tasikmalaya Regency. The methods used at this stage are (1) showing direct evidence through checking for tension; (2) changes in perception, partners receive information through observing, demonstrating, and using media or props. The method used at this stage is counseling (3) Adoption. After awareness of heart disease in patients with hypertension, an increase in the average pretest value from 51.52 to 93.22. Awareness of heart disease was able to detect the incidence of hypertension in the community and increase community participation to check blood pressure and reduce blood pressure and prevent heart disease.
Abstrak
Masyarakatyang mempunyai tekanan darah dengan kategori hipertensi memiliki potensi menderita penyakit jantung koroner (PJK). Deteksi dini PJK salah satunya dengan melakukan pemeriksaan tekanan darah. Tujuan dari pengabdian masyarakat untuk meningkatkan pengetahuan, sikap dan ketrampilan mitra untuk melakukan deteksi dini PJK yaitu penyakit yang disebabkan adanya plak menumpuk di dalam arteri koroner yang mensuplai oksigen ke otot jantung. Metode yang digunakan yaitu penyuluhan untuk memberikan edukasi PJK dan pelatihan pemeriksaan tekanan darah dengan praktek langsung 
menggunakan tensimeter. Hasil menunujukkan bahwa penyuluhan untuk memberikan edukasi mengenai PJK mampu meningkatkan pengetahuan pada mitra sebesar 25,4\%. Pelatihan pemeriksaan tekanan darah untuk menentukan masuk kategori hipertensi atau tidak. dengan menggunakan tensimeter mampu meningkatkan ketrampilan mitra sebesar $41.7 \%$ Hasil uji statistik wilcoxon menunjukkan nilai $\mathrm{p}$ value 0.00 artinya ada perbedaan yang signifikan antara pengetahuan sebelum dan sesudah pemberian penyuluhan risiko menderita penyakit jantung pada penderita hipertensi. Pengetahuan mitra meningkat ke arah positif dan berpersepsi ke arah lebih baik dalam mengetahui risiko menderita penyakit jantung pada penderita hipertensi.Simpulan dari pengabdian ini yaitu deteksi dini penyakit jantung mampu mendeteksi kejadian hipertensi di masyarakat. Peningkatan pengetahuan dan ketrampilan mitra pengabdian dapat mendorong partisipasi masyarakat untuk melakukan pencegahan PJK melalui pemeriksaan tekanan darah secara rutin.

\section{PENDAHULUAN}

Penyakit jantung koroner (PJK) adalah penyakit yang disebabkan adanya plak yang menumpuk di dalam arteri koroner yang mensuplai oksigen ke otot jantung. Penyakit ini termasuk bagian dari penyakit kardiovaskuler yang paling umum terjadi. Penyakit kardiovaskuler merupakan gangguan dari jantung dan pembuluh darah termasuk stroke, penyakit jantung rematik dan kondisi lainnya (WHO, 2013). Penyakit jantung koroner mempunyai komplikasi-komplikasi tersendiri seperti aritmia, gagal jantung kongestif, infark miokardial, dan kematian (Kumar P., 2012).

Penelitian faktor risiko dominan penderita jantung koroner di Indonesia menggunakan data sekunder dari Survei Riset Kesehatan Dasar Indonesia tahun 2013 didapatkan dari 722.329 responden usia $\geq 15$ tahun didapat prevalensi penyakit jantung koroner sebesar 1,5 \% (95\% CI 1,4-1,5). Prevalensi penyakit jantung koroner terlihat lebih besar pada perempuan yaitu 1,6\% sedangkan pada laki-laki hanya 1,3\%. Penderita jantung koroner lebih banyak di perdesaan. Jenis kelamin perempuan berisiko 1,22 kali terjadinya penyakit jantung koroner dengan $\mathrm{p}=0,0001$, 95\% CI 1,17-1,27.

Namun demikian, akibat pengaruh budaya dan cara pandang masyarakat, kesadaran akan pentingnya kesehatan jantung pada kaum perempuan masih rendah, masyarakat sering beranggapan bahwa kesehatan suami atau kaum laki-laki lebih penting. Fakta sekarang American Heart Association (AHA) mengatakan lebih dari $1 / 3$ perempuan dewasa menderita salah satu bentuk penyakit kardiovaskuler terutama penyakit jantung koroner dan jumlah kematian pada perempuan melebihi laki-laki. Tahun 2012, sekitar $56 \%$ penyebab kematian perempuan adalah penyakit kardiovaskuler dan terbanyak adalah penyakit jantung koroner (Salam T, 2013).

Masyarakat dengan status ekonomi rendah (miskin) pada kuintil 1 dan 2, lebih berisiko dibandingkan dengan status ekonomi menengah ke atas (tidak miskin) pada kuintil 3,4 dan 5 . Responden dengan pendidikan kurang tinggi lebih berisiko dibandingkan yang berpendidikan tinggi. Penderita hipertensi berisiko 5,34 kali mengalami PJK dibanding yang tidak (Lannywati, 2016).

Townsend (2013) menyatakan bahwa penderita penyakit jantung koroner di negara berkembang terjadi disebabkan oleh hipertensi. Hal ini menunjukkan bahwa hipertensi adalah salah satu faktor risiko utama terjadinya penyakit jantung koroner. Jumlah penderita penyakit jantung koroner terus meningkat di Indonesia. Penyakit ini dapat menimbulkan rasa kesakitan, kecacatan dan beban sosial ekonomi bagi keluarga penderita, masyarakat, dan negara. Oleh karena itu pemerintah serius dalam upaya mengendalikan penyakit jantung koroner melalui program bersediapun kegiatan tahunan yang diselenggarakan. 
Kabupaten Tasikmalaya merupakan salah satu kabupaten dengan angka kejadian hipertensi yang tinggi. Berdasar profil Puskesmas Monanjaya dan Puskesmas Cineam tahun 2018, penyakit hipertensi merupakan sepuluh besar penyakit yang banyak diderita masyarakat. Kondisi tersebut mendorong tim pelaksana untuk berkontribusi dalam upaya pengendalian penyakit jantung koroner melalui kegiatan pengabdian Deteksi Dini Penyakit Jantung Koroner. Tim memberikan penyuluhan dalam mengedukasi masyarakat tentang hipertensi dan penyakit jantung koroner sehingga dapat mendorong penderita hipertensi untuk mencegah terjadinya penyakit jantung dengan melakukan pemeriksaan.

Deteksi dini penyakit jantung merupakan bagian dari manajemen terhadap terjadinya penyakit tidak menular khususnya penyakit jantung. Pelaksanaan kegiatan pengabdian kali ini dilakukan dengan melibatkan 2 (dua) kelompok masyarakat yaitu ibu-ibu PKK di Desa Kalimanggis kecamatan Manonjaya dan ibu ibu PKK di Desa Madiasari Kecamatan Cineam Kabupaten Tasikmalaya. Kegiatan penyuluhan disampaikan kepada seluruh ibu-ibu PKK di desa Kalimanggis dan Madiasari sedangkan pelatihan pemeriksaan tekanan darah menggunakan tensimeter diberikan pada ibu ibu yang menderita hipertensi.

Hasil pertemuan dan diskusi dengan mitra, disepakati bahwa upaya pemecahan masalah dilakukan dengan; (1) deteksi dini penyakit hipertensi dengan cara pengukuran tekanan darah, (2) edukasi kepada ibu-ibu mengenai faktor risiko penyakit jantung pada penderita hipertensi 3) Pelatihan pengukuran tekanan darah menggunakan tensimeter pada ibu-ibu penderita hipertensi.

\section{METODE PELAKSANAAN}

Mitra dalam kegiatan pengabdian kali ini adalah ibu-ibu PKK di Desa Kalimanggis kecamatan Manonjaya dan Desa Madiasari Kecamatang Cineam Kabupaten Tasikmalaya. Upaya yang dilakukan oleh tim pengusul agar mitra memiliki kesadaran terhadap pencegahan penyakit jantung sehingga bersedia melakukan pemeriksaan tekanan darah secara teratur dilakukan dengan menggunakan prinsip
PSP (pengetahuan, sikap, praktek). Prinsip pembelajaran yang menekankan bahwa transfer Ipteks dimulai dengan transfer knowledge, perubahan persepsi atau sikap dan mengadopsi melalui praktek.

Transfer Ipteks tersebut meliputi tahapan kegiatan (1) transfer knowledge yaitu memberikan informasi dengan mendengarkan, menyimak, dan menanggapi. Metode yang digunakan pada tahap ini adalah menunjukkan bukti langsung melalui pemeriksaan tensi; (2) perubahan persepsi, mitra menerima informasi melalui mengamati, demonstrasi, dan penggunaan media atau alat peraga. Metode yang digunakan pada tahap ini adalah penyuluhan (3) Adopsi, mitra menerima informasi dengan berlatih dan menerapkan. Metode yang dilakukan pada tahap ini adalah pelatihan penggunaan tensimeter pada ibu ibu yang menderita hipertensi.

Tujuan penyampaian informasi pada setiap tahapan adalah sebagai berikut; (1) Identifikasi penyakit hipertensi dengan tujuan untuk melakukan deteksi dini terhadap penyakit hipertensi. (2) Sosialisasi bertujuan untuk memberikan pengetahuan dan pemahaman kepada mitra mengenai risiko penyakit jantung pada penderita hipertensi, dilakukan dengan penyuluhan yang bertujuan agar mitra bersikap atau berpersepsi baik sehingga bersedia melakukan pemeriksaan tekanan darah secara teratur (3) pelatihan dilakukan untuk memastikan mitra dapat mampu menggunakan alat pengukur tensi. Melalui tahapan-tahapan tersebut diharapkan proses transfer Ipteks yang diberikan dapat dilakukan secara rutin dan berkelanjutan, menjadi kebiasaan yang dilakukan oleh mitra dan mitra dapat membagikan kemampuan yang dimiliki kepada ibu-ibu lain yang menderita hipertensi.

Adapun tahapan pelaksanaan pemberian Ipteks bagi bina masyarakat adalah sebagai berikut:

a. Pemeriksaan tensi dengan tujuan untuk melakukan deteksi dini terhadap penyakit hipertensi

b. Penyuluhan risiko penyakit jantung pada penderita hipertensi, untuk memberikan pengetahuan, pemahaman sehingga mendorong sikap atau persepsi baik untuk 
bersedia melakukan pemeriksaan tekanan darah secara teratur

c. Pelatihan pengukuran tekanan darah menggunakan tensimeter untuk memastikan mitra mampu menggunakan alat pengukur tekanan darah (tensimeter) yang dibagikan.

Melalui tahapan-tahapan tersebut diharapkan proses transfer Ipteks yang diberikan dapat berkelanjutan, menjadi kebiasaan yang dilakukan oleh mitra dan mitra dapat membagikan kemampuan yang dimiliki kepada ibu-ibu lain yang menderita hipertensi.

\section{HASIL DAN PEMBAHASAN}

Deteksi dini penyakit jantung koroner diikuti oleh ibu-ibu yang berasal dari 2 Desa yaitu Desa Kalimanggis Kecamatan Manonjaya dan Desa Madiasari Kecamatan Cineam. Desa Kalimanggis terletak $10 \mathrm{~km}$ dari Universitas Siliwangi sedangkan desa Madiasari terletak 15 km dari Universitas Siliwangi. Jumlah peserta pengabdian masyarakat sebayak 59 orang. Umur rata rata peserta deteksi dini penyakit jantung 46 tahun dengan umur paling muda 22 tahun dan umur paling tua 74 tahun dan standar deviasi 12.

\section{Pelaksanaan Kegiatan}

Kegiatan pengabdian dimulai dengan melaksanakan pembahasan rencana kegiatan pengabdian masyarakat yang dihadiri pengurus PKK desa Kalimanggis dan desa Madiasari. Hasil dari kegiatan ini adalah adanya kesepakatan waktu pelaksanaan pengabdian masyarakat yang dimulai pada tanggal 22 Juni 2019 di Balai Desa Kalimanggis dan tanggal 29 Juni 2019 di Balai Desa Madiasari. Selanjutnya dilakukan permohonan perijinan di Desa Kalimanggis dan Desa Madiasari, Kecamatan Manonjaya dan Kecamatan Cineam, Puskesmas Manonjaya dan Puskesmas Cineam. Detail pelaksanan kegiatan IbBM yang dilakukan sebagai berikut :

a. Pemeriksaan tekanan darah

Kegiatan pemeriksaan tekanan darah bertempat dilakukan oleh tim pengabdian masyarakat dengan menggunakan tensimeter digital merek Omron dan diikuti oleh 59 orang. Hasiil pemeriksaan tensi didapatkan bahwa sebanyak 17 orang peserta pengabdian IbBM (28.81\%) menderita hipertensi.

b. Penyuluhan risiko penyakit jantung pada penderita hipertensi

Penyuluhan risiko penyakit jantung pada penderita hipertensi dilakukan diawali dengan pemberian pre tes yang berisi 10 soal kemudian diberikan penyuluhan. Materi penyuluhan yang diberikan meliputi besarnya masalah penyakit jantung di dunia dan di Indonesia, faktor risiko pemicu terjadinya serangan jantung, hipertensi dan risiko menderita penyakit jantung, identifikasi penyakit hipertensi, cara mencegah dan mengendalikan hipertensi agar tidak menderita penyakit jantung. Setelah selesai penyuluhan kemudian peserta diberikan post test.

Penyuluhan risiko penyakit jantung pada penderita hipertensi dilakukan di Balai Desa Kalimanggis pada tanggal 22 Juni 2019 yang dihadiri oleh Kepala Desa Kalimanggis yang kebetulan juga perempuan dan $29 \mathrm{ibu}$ PKK desa Kalimanggis.

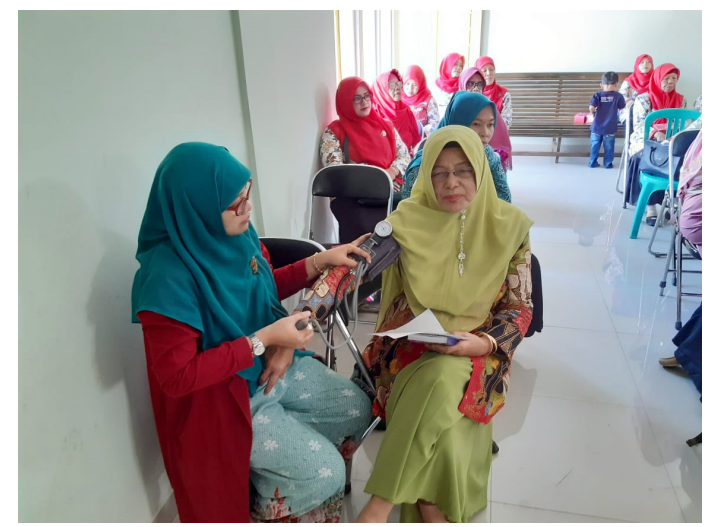

Gambar 1 Pemeriksaan Tekanan Darah

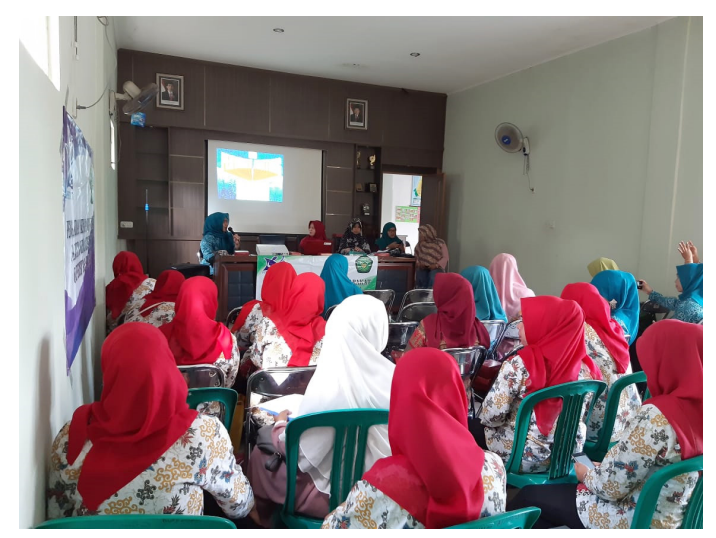

Gambar 2. Penyuluhan Risiko Penyakit Jantung 
Penyuluhan risiko penyakit jantung pada penderita hipertensi dilakukan di Balai Desa Madiasari dihadiri oleh ketua tim penggerak PKK yang juga merupakan bidan yang bertugas di Puskesmas Cineam Kabupaten Tasikmalaya.Tim melakukan pre test dan post test untuk mengetahui tingkat pemahaman mitra tentang penyakit jantung koroner.Pre test dan post test dilakukan secara tertulis karena seluruh responden masih mampu membaca dan menulis. Hasilnya terlihat dalam tabel 1.

Berdasar tabel 1, mitra sudah pernah mendengar bahwa penyakit jantung merupakan pembunuh nomor satu di dunia. Sebagian besar responden sudah mengetahui bahwa fungsi jantung adalah memompa darah. Hanya sedikit mitra yang mengetahui gejala penyakit jantung sebelum penyuluhan (39\%), setelah penyuluhan $91.5 \%$ mitra mengetahui gejala penyakit jantung. Kurang dari setengah responden yang mengetahui bahwa faktor risiko terjadinya penyakit jantung adalah konsumsi lemak, kurang olahraga dan hipertensi. Belum semua mintra mengetahui bahwa Penyakit jantung dapat terjadi jika tekanan darah tinggi.Hanya sedikit mitra (3.4\%) mengetahui batas tekanan darah sistole dan diastole disebut hipertensi. Sedikit mitra tidak mengetahui (18.6\%) bahwa hipertensi dapat berisiko terkena penyakit jantung koroner.

Penyuluhan deteksi dini penyakit jantung mampu meningkatkan pengetahuan sebagian besar responden tentang penyakit jantung, tugas jantung, gejala penyakit jantung, faktor pemicu, mengetahui cara pencegahan hipertensi dan dapat menjelaskan batas tekanan darah disebut hipertensi. Hal yang masih kurang dipahami oleh peserta adalah terkait bagaimana mekanismenya hipertensi dalam menyebabkan penyakit jantung.

Mitra mampu melakukan pemeriksaan tekanan darah dengan tensimeter dan mengetahui indikator menderita hipertensi jika tekanan darah sistol lebih dari atau sama dengan 140/90 $\mathrm{mmHg}$. Mitra mendengarkan, menyimak, dan menanggapi materi tentang penyakit hipertensi dan risikonya menderita penyakit jantung. Terbukti dengan banyaknya pertanyaan yang muncul antara lain makanan apa yang dapat mencegah hipertensi, apa yang harus dilakukan jika menderita hipertensi, apa bedanya nyeri dada karena penyakit jantung dan nyeri dada karena penyakit lain serta berbagai pertanyaan lainnya.

Tabel 1 Distribusi Hasil Soal Pretes dan Postes

\begin{tabular}{clcccc}
\hline \multirow{2}{*}{ No. Soal Tes } & \multicolumn{1}{c}{ Pretes } & \multicolumn{2}{c}{ Postes } \\
\cline { 2 - 6 } & n & \% & n & \% \\
\hline 1 & $\begin{array}{l}\text { Pengetahuan tentang Penyakit sebagai pembunuh nomor satu } \\
\text { di dunia }\end{array}$ & 43 & 72.9 & 58 & 98.3 \\
2 & $\begin{array}{l}\text { Pengetahuan mengenai tugas jantung manusia sebagai organ } \\
\text { untuk memompa darah }\end{array}$ & 55 & 98.2 & 58 & 98.3 \\
3 & Pengetahuan mengenai gejala gejala penyakit Jantung & 23 & 39,0 & 54 & 91,5 \\
4 & Pengetahuan mengenai faktor pemicu terjadinya serangan & 28 & 47.5 & 56 & 94.9 \\
& jantung & & & & \\
5 & Penyakit yang dapat terjadi jika tekanan darah tinggi & 44 & 74.6 & 59 & 100 \\
6 & Cara mencegah Hipertensi & 57 & 96.6 & 58 & 98.3 \\
7 & Lama aktifitas fisik minimal per hari untuk menjaga kesehatan & 37 & 62.7 & 59 & 100 \\
& jantung & & & & \\
8 & Batas Normal Tekanan darah sistole & 2 & 3.4 & 55 & 93.2 \\
9 & Batas Normal Tekanan darah diastole & 19 & 32.2 & 59 & 100 \\
10 & Hipertensi menyebabkan penyakit jantung & 11 & 18.6 & 33 & 55.9 \\
\hline
\end{tabular}


Mitra mendapatkan informasi dengan menyimak materi yang disampaikan dan terjadi peningkatan pengetahuan tentang PJK sebesar 41,70\% yaitu dari $51.52 \%$ menjadi 93,22\% ngabdian masyarakat juga dilakukan dengan kampanye makan buah dan mendemonstrasikannya kepada mitra yaitu makan buah pisang bersama. Harapannya masyarakat terutama yang menderita hipertensi selalu menyediakan sayur dan buah buahan lokal seperti pisang yang banyak tersedia dan murah.

Melalui tahapan-tahapan tersebut diharapkan proses transfer pengetahuan yang diberikan dapat berkelanjutan, menjadi kebiasaan yang dilakukan oleh mitra dan mitra dapat membagikan kemampuan yang dimiliki kepada ibuibu lain yang menderita hipertensi. Untuk mengevaluasi bahwa mitra mengetahui hipertensi berisiko menderita penyakit jantung diketahui dengan memberikan soal post test. Soal tes yang diberikan berisikan 10 pertanyaan mengenai penyakit jantung sebagai pembunuh nomor satu, pengetahuan mengenai tugas jantung bagi manusia, pengetahuan mengenai gejala gejala menderita penyakit jantung, pengetahuan mengenai faktor pemicu terjadinya serangan jantung, penyakit yang dapat terjadi jika tekanan darah tinggi, Cara mencegah hipertensi, lama aktivitas fisik minimal per hari untuk menjaga kesehatan jantung, batas normal tekanan darah sistole dan diastole, serta bagaimana penyakit hipertensi dapat menyebabkan penyakit jantung.

Keberhasilan mitra diketahui dari hasil perbandingan antara nilai tes pengetahuan mitra sebelum dan sesudah menerima kegiatan sosialisasi risiko menderita penyakit jantung pada penderita hipertensi. Hasil uji normalitas Kolmogorof Smirnov menunjukkan nilai $\mathrm{p}$ value hasil pre test 0.11 artinya data berdistribusi normal dan nilai postes mempunyai p value 0.00 artinya data berdistribusi tidak normal sehingga uji statistik yang digunakan untuk mengetahui berbedaan nilai rata rata pretes dan postes adalah uji statistik wilcoxon.
Tabel 2 Penghitungan Statistik Nilai Pretes dan Postes

\begin{tabular}{lcc}
\hline \multicolumn{1}{c}{ Nilai } & $\begin{array}{c}\dot{\mathbf{x}} \pm \text { SD } \\
\text { (min-max) }\end{array}$ & P Value \\
\hline Pretes & $51.5 \pm 13.5$ & 0.00 \\
& $(30-80)$ & \\
Postes & $93.2 \pm 8.8$ & \\
& $(60-100)$ & \\
\hline
\end{tabular}

Hasil uji statistik wilcoxon didapatkan nilai $\mathrm{p}$ value 0.00 yang artinya ada perbedaan yang signifikan antara nilai rata rata tes pengetahuan sebelum dan sesudah pemberian penyuluhan risiko menderita penyakit jantung pada penderita hipertensi. Ada peningkatan nilai rata rata post test sebesar $41,7 \%$ dari nilai rata rata pretes $51,5 \%$ meningkat menjadi 93,2\%. Peningkatan ini menunjukkan bahwa pengetahuan mitra meningkat ke arah positif, artinya mitra berpersepsi ke arah lebih baik dalam mengetahui risiko menderita penyakit jantung pada penderita hipertensi.

Ibu-ibu mengetahui bahwa penyakit jantung adalah pembunuh nomor satu di dunia sehingga diharapkan nantinya ibu mempunyai kesadaran untuk melakukan upaya pencegahan penyakit jantung. Ibu mengetahui bahwa tugas jantung sangat penting sebagai alat untuk memompa darah sehingga diharapkan ibu-ibu akan selalu menjaga kesehatan jantung. Ibuibu juga mengetahui gejala penyakit jantung, sehingga diharapkan apabila merasakan nyeri dada atau melihat ada anggota keluarganya yang merasakan nyeri dada, sesak nafas, mudah lelah, pusing dan pingsan, segera berobat ke fasilitas pelayanan kesehatan.

Ibu-ibu juga mengetahui bahwa faktor yang memicu terjadinya penyakit jantung adalah tekanan darah tinggi atau hipertensi sehingga diharapkan melakukan pengukuran tekanan darah untuk mengetahui menderitahipertensiatau tidak. Ibu-ibu juga meningkat pengetahuannya mengenai cara mencegah hipertensi salah satunya dengan mengkonsumsi sayur dan 
buah buahan minimal 5 porsi per hari serta melakukan aktifitas fisik minimal 30 menit per hariatau 150 menit per minggu untuk mencegah terjadinya hipertensi dan penyakit jantung (Kemenkes, 2015).

Konsumsi buah dan sayur $>400$ gr/hari dapat menurunkan risiko hipertensi. Rekomendasi yang cukup untuk mengonsumsi buah dan sayur yaitu sebanyak 400 gram atau 3-5 porsi sehari. Hal ini tidak saja disebabkan oleh aktivitas antioksidan dalam buah dan sayur, tetapi juga karena adanya komponen lain seperti serat, mineral Kalium, dan Magnesium. Konsumsi sayur dan buah akan mempercepat rasa kenyang. Keadaan ini menguntungkan karena dapat mengurangi pemasukan energi dan obesitas, selain itu kandungan serat dalam buah dan sayur akan menurunkan risiko hipertensi (WHO, 2014).

Aktivitas fisik dapat mempengaruhi tekanan darah, karena seseorang yang memiliki aktivitas fisik yang rendah cenderung memiliki tekanan darah tinggi. Kriteria aktivitas fisik aktif yaitu ketika seseorang melakukan aktivitas fisik berat atau sedang atau keduanya. Sedangkan kriteria kurang aktif ketika individu tidak melakukan aktivitas fisik sedang maupun berat. Perilaku sedentari seperti duduk atau berbaring baik di tempat kerja (kerja di depan komputer, membaca), di rumah (menonton $\mathrm{TV}$, bermain game), di perjalanan/transportasi, tetapi tidak termasuk waktu tidur (Khairani, , 2018).

Ibu-ibu juga mengetahui bahwa hipertensi jika tekanan darah sistolik lebih dari atau sama dengan $140 \mathrm{mmHg}$ dan tekanan darah distolik lebih dari atau sama dengan 90 mmHg. Harapannya ibu-ibu akan menyadari menderita hipertensi jika tekanan darahnya lebih dari atau sama dengan 140/90 mmHg sehingga akan melakukan pengobatan di fasilitas pelayanan kesehatan dan mengikuti kegiatan posbindu (pos pembinaan terpadu) penyakit tidak menular (Kemenkes, 2015).

Semakin tinggi tekanan darah, semakin tinggi risiko kerusakan jantung dan pembuluh darah. Hipertensi adalah penyebab paling penting yang dapat dicegah dari penyakit. Jika dibiarkan tidak terkendali hipertensi dapat menyebabkan serangan jantung, pembesaran jantung dan akhirnya gagal jantung. Pembuluh darah dapat mengembang membentuk tonjolan (aneurisma) dan cenderung tersumbat dan pecah. Konsekuensi kesehatan dari hipertensi dapat diperparah oleh faktorfaktor lainyangmeningkatkan kemungkinan serangan jantung. Penderita hipertensi dapat mengalami krisis hipertensi. Krisis hipertensi adalah sebuah sindroma klinis yang ditandai dengan peningkatan tekanan darah mendadak pada pendertia hipertensi jika tekanan darah sistolik (TDS) $>180$ $\mathrm{mmHg}$ dan tekanan darah diastolik (TDD) $>120$ mmHg. Krisis Hipertensi biasanya terjadi jika lama menderita hipertensi antara 1-5 tahun (Sri W, 2018).

Konsumsi sayur dan buah lokal sangat diutamakan, tidak perlu membeli namun dapat memetik dari pekarangan, atau kebun sendiri. Pangan lokal sesuai dengan kebiasaan dan sosial budaya setempat, tanpa perlu biaya yang mahal namun memiliki kandungan gizi yang tinggi. Di samping itu, dapat melanjutkan konsumsi pangan lokal secara mandiri (Lilik Hidayanti, 2019).

Gejala penyakit jantung koroner termasuk nyeri dada dan kesulitan bernapas, terutama dengan aktivitas. Namun, beberapa orang yang memiliki penyakit jantung tidak memiliki gejala sehingga pengetahuan tentang faktor risiko penyakit jantung sangat penting sebagai upaya pencegahan. Secara umum, orang yang berisiko lebih tinggi karena menderita hipertensi mendapat manfaat lebih karena mengetahui bahwa menderita hipertensi sehingga diharapkan pengetahuan tersebut mendorong terjadinya perubahan perilaku hidup sehat dan rajin melakukan pengontrolan terhadap tekanan darah.

Hipertensi meningkatkan beban kerja jantung, menyebabkan ototjantungmenebal dan menjadi lebih kaku. Pengerasan otot jantung ini tidak normal dan menyebabkan jantung berfungsi tidak normal. Ketika tekanan darah tinggi terjadi bersamaan 
dengan obesitas, merokok, kadar kolesterol darah tinggi atau diabetes, risiko serangan jantung semakin meningkat (https://www. heart.org/en/healthtopics/heart-attack/ understand-your-risks-to-prevent-a-heartattack)

c. Pelatihan pemeriksaan tekanan darah dengan menggunakan tensi meter.

Pelatihan ini dilakukan terhadap 11 orang ibu yang menderita hipertensi berdasar hasil pemeriksaan tekanan darah yang telah dilakukan sebelumnya. Pelatihan bertujuan untuk memastikan mitra bahwa mampu menggunakan alat pengukur tensi secara mandiri. Pelatihan dilaksanakan setelah pelaksanaan sosialisasi risiko menderita penyakit jantung pada penderita hipertensi.

Pada saat pelatihan tim pelaksana terlebih dahulu membagikan leaflet yang berisi tentang materi penyakit jantung dan hipertensi lalu kemudian melakukan demonstrasi cara pengukuran tensi. Dalam kegiatan pelatihan juga dilakukan sesi tanya jawab dengan peserta pelatihan. Beberapa pertanyaan yang ditanyakan adalah pada saat mengukur tensi dapat dilakukan sendiri atau harus dibantu orang lain, pada saat diukur tensi boleh berbicara atau tidak.

Selanjutnya peserta pelatihan berlatih menggunakan alat tensi. Tim pengabdian juga menitipkan tensimeter pada ketua tim penggerak PKK dan meminta agar penderita hipertensi yang melakukan pemeriksaan tensi pada saat dilakukan kegiatan PKK pada bulan Juli tahun 2019.

Sedangkan untuk mengevaluasi bahwa mitra mampu menggunakan alat pengukur tensi, meminta 2 orang peserta mempraktekkan cara mengukur tensi dan menyebutkan berapa tekanan darah sistole dan berapa tekanan darah diastole serta menyebutkan tekanan darahnya tinggi atau tidak.

Hasi Riskesdas 2018 menunujukkan bahwa terjadi peningkatan prevalensi faktor risiko penyakit jantung dari hipertensi dari $25.8 \%$ menjadi $34.1 \%$ pada Riskesdas (Kemenkes 2018). Tingginya prevalensi hipertensi di Indonesia menunjukkan pentingnya masyarakat untuk selalu mewaspadai tekanan darah tinggi, salah satunya dengan melakukan pemeriksaan tekanan darah dan mencegah hipertensi.

d. Kegiatan Pemberdayaan

Kegiatan pemberdayaan bertujuan agar peserta pelatihan bersedia melanjutkan kegiatan pengabdian masyarakat yaitu melakukan pemeriksaan tensi secara teratur minimal 1 bulan sekali dengan menggunakan alat tensimeter yang ada di ketua tim penggerak PKK desa dan mencatat hasil pemeriksaan tensi di buku hasil pemeriksaan tensi.

Mitra mengadopsi perilaku kesadaran risiko menderita penyakit jantung pada hipertensi dilakukan dengan cara :

1) Melakukan monitoring untuk melakukan pengecekan apakah penderita hipertensi yang sudah dilatih melakukan pemeriksaan tekanan darah setelah satu bulan

2) Perubahan tekanan darah mitra setelah satu bulan.

Tabel 3. Perubahan Tekanan darah dalam Kegiatan Monitoring Setelah Satu Bulan

\begin{tabular}{lcc}
\hline Tekanan darah & Jumlah & $\mathbf{\%}$ \\
\hline Tetap & 4 & 36,4 \\
Menurun & 7 & 63,6 \\
\hline Total & 11 & 100 \\
\hline
\end{tabular}

Hasil kegiatan monitoring didapatkan pada bulan Agustus 2019 sebanyak 11 orang dari 17 orang yang menderita Hipertensi didapatkan sebanyak 7 orang dari 11 orang yang periksa $(63,6 \%)$ mengalami penurunan tekanan darah.

\section{SIMPULAN}

Penyuluhan risiko penyakit jantung koroner pada penderita hipertensi dapat meningkatkan pengetahuan mitra sebesar $41,7 \%$. Deteksi dini penyakit jantung dapat mengetahui kejadian hipertensi di masyarakat. Partisipasi masyarakat meningkat untuk melakukan pemeriksaan tekanan darah, menurunkan tekanan darah dan mencegah terjadinya penyakit jantung yang ditandai dengan hasil monitoring takanan darah 
dimana $63,6 \%$ penderita hipertensi mengalami penurunan tekanan darah.

\section{PERSANTUNAN}

Penulis mengucapkan terima kasih kepada Lembaga Penelitian dan Pengabdian masyarakat Universitas Siliwangi yang telah memberikan hibah pengabdian Ipteks bagi bina Masyarakat (IbBM), Kepala Desa Kalimanggis Kecamatan Manonjaya dan Kepala Desa Madiasari Kecamatan Cineam Kabupaten Tasikmalaya, PKK Desa Kalimanggis dan Desa Madiasari, Puskesmas Manonjaya dan Puskesmas Cineam, mahasiswa kesehatan masyarakat yang terlibat dalam kegiatan ini.

\section{REFERENSI}

Delima, 2009, prevalensi dan factor determinan penyakit jantung di Indonesia, Bul. Penelit. Kesehat., Vol. 37, No. 3,2009 : 142 - 159

Khairani, N., Effendi, S. U., \& Utamy, L. W. (2018). Aktivitas Fisik Dan Kejadian Obesitas Sentral Pada Wanita Di Kelurahan Tanah Patah Kota Bengkulu. Chmk Nursing Scientific Journal, 2(1), 11-17. https://Doi.Org/10.1016/B978-0-12-375073-0.50041-5.)

Kemenkes, 2015, Petunjuk Teknis Surveilans Penyakit Tidak Menular, Kementerian Kesehatan $\mathrm{Ri}$ Direktorat Jenderal Pengendalian Penyakit Dan Penyehatan Lingkungan Direktorat Pengendalianpenyakit Tidak Menular

Kemenkes, 2018, Kemenkes 2018, HASIL UTAMA. RISKESDAS 2018. Kementerian Kesehatan. Badan Penelitian dan Pengembangan Kesehatan. 1. Balitbangkes, 071118.

Kumar P., 2012. Coronary Artery Disease Clinical Medicine Eight Edition, International Edition, Spain. 723-724

Ghani, Lannywati., Made Dewi Susilawati dan Harli Novriani, 2016, Faktor Risiko Dominan Penyakit Jantung Koroner di Indonesia, Buletin Penelitian Kesehatan, Vol. 44, No. 3, September 2016 : 153164.

Hidayanti, Lilik., dan Sri Maywati, 2019, Program Kemitraan: PMT Penyuluhan Pangan Lokal di Desa Sukarame Kecamatan Sukarame Kabupaten Tasikmalaya Jawa Barat, Warta LPM, Vol 22, No. 1, Maret 2019: 38-46.

Salam, T. , Watson KE, 2013,Predictor of cardiovascular risk in women. Womens Health 2013; 9(5): 491498.

Townsend,N, 2013, Medical Risk Factor Coronary Heart Statistics Acomoendium of Health Statistic. Departement of Health. Public, University Oxford;2013.

WHO, 2013, About Cardiovascular diseases. World Health OrganizLation. Geneve. [cited 2016 Apr 26]. Available from: http://www.who. int/cardiovascular_diseases/about_cvd/en/

Wahyuningsih, S, 2018, Pengaruh Derajat Hipertensi, Lama Hipertensi dan Hiperlipidemia Dengan Gangguan Jantung Dan Ginjal Pasien Hipertensi Di Posbindu Cisalak Pasar, Jurnal Kesmas Indonesia, Volume 10, Nomor 1, Januari 2018, Hal. 54-67

World Health Organization. Global Status Report On Noncommunicable Diseases. Geneva: WHO, 2014.

https://www.heart.org/en/healthtopics/heart-attack/understand-your-risks-to-prevent-a-heartattack. 